\title{
Measurement and prediction on thermal conductivity of fused quartz
}

\author{
Xin Rui Zhang ${ }^{1}$, Gang Qiang Kong ${ }^{1,2 *}$, Le Hua Wang ${ }^{2} \&$ Xiao Liang X ${ }^{2}$
}

Thermal conductivity of soil is a basic physical property related to heat conduction, and also is one of parameters widely applied in geotechnical engineering. The effect of gradation on the thermal conductivity of fused quartz was analyzed by thermal needle tests. The different particle size with the same uniformity coefficient $\left(C_{u}=3.2\right)$ and different uniformity coefficient for the same particle size $(0.10 \sim 1.00 \mathrm{~mm})$ were considered in this study. It shows that the thermal conductivity of fused quartz decreases with the decreasing of the mean particle size and with the increasing of the porosity. Simple modified methods to estimate the value of thermal conductivity are proposed, and had been demonstrated successfully by conducting fused quartz, carbonate sand and Ottawa sand.

Management of natural resources is becoming one of the crucial issues of the 21 st Century. The global demand for clean and renewable energy sources is growing because they represent one of the most effective tools against climate change. As a kind of renewable energy, shallow geothermal energy not only has huge reserves, no pollution and no carbon emissions, but also is easy to develop ${ }^{1-3}$. In order to save underground space, geotechnical engineers combine ground source heat pump technology with underground structures (such as pile, tunnel, etc.) as energy geological structures. It is believed that the energy geological structure has made a positive contribution to regulating the environmental conditions of the building. The working process of energy geostructures is a coupling problem of stress field, displacement field, temperature field, and seepage field. The efficiency of heat transfer affects the efficiency of energy geostructures. Thermal conductivity of soil is a basic physical property related to heat conduction.

Transparent soil consists of an aggregate and a refractive index matched fluid ${ }^{4}$. When fully saturated, the particles appear invisible and allow light to pass, enabling visualization through the "soil"4. Both fine (clay) and coarse-grained (sands/gravels) materials were developed, and their mechanical properties were summarized by Iskander et al. ${ }^{5}$. Combined with laser and particle image velocimetry, non-invasive measurements can be made to investigate internal flow, deformation of transparent soil around the structure, grouting, and thermal reponse of sands in geotechnical engineering ${ }^{6}$. The heat transfer processes of energy pile surrounding soil were measured through transparent soil ${ }^{7,8}$. However, previous literature has not studied the thermal properties of fused quartz and its difference in thermal behavior from that of natural soils. Measured thermal conductivity of fused quartz will also be beneficial to future studies on thermal reponses of granular materials using transparent sand.

Thermal conductivity refers to the heat flow per unit area per unit time in a unit temperature gradient (with unit: $\mathrm{W} /(\mathrm{m} \cdot \mathrm{K})$ ). It depends on the mineral composition, water content, dry density, particle composition and morphology, temperature, etc. ${ }^{9,10}$. De Vries ${ }^{11}$ introduced soil particle shape coefficient $g_{s}$ in his model of heat transfer. Tarnawski et al. ${ }^{12}$ provided that particle shape values $\left(g_{\mathrm{s}}\right)$ for C-109 is 0.12 , and for C-190 is 0.125 . Rzhevsky et al. ${ }^{13}$ found that the thermal conductivity decreased as the particle size of the material decreases. Midttomme et al. ${ }^{14}$ found that the particle content $>63 \mu \mathrm{m}$ had the greatest effect on the measured thermal conductivity. Xiao et al..$^{15}$ found that the gradation effect on the thermal conductivity is attributed to the same intrinsic mechanism, which is independent of the porosity. An important internal factor that has not been fully investigated is the effect of gradation, which is a relevant topic in the study of application of transparent soils. Hence, a series of laboratory tests were performed to investigate the influence of the gradation and porosity on the thermal conductivity of the fused quartz. This study reviews literature models for the thermal conductivity of granular materials, experimentally determines the thermal conductivity of fused quartz using the thermal needle probe method, and assesses the accuracy of predicting the measured data using the existed models. The results hightlight the inadequacy of these models in characterizing the measured thermal conductivity of fused quartz and thus a new fitting formula based on literature models is suggested.

${ }^{1}$ Key Laboratory of Ministry of Education for Geomechanics and Embankments, Hohai University, Nanjing, P.R. China. ${ }^{2}$ Key Laboratory of Geological Hazards on Three Gorges Reservoir Area of Ministry of Education, China Three Gorges University, Yichang, P.R. China. *email: gqkong1@163.com 


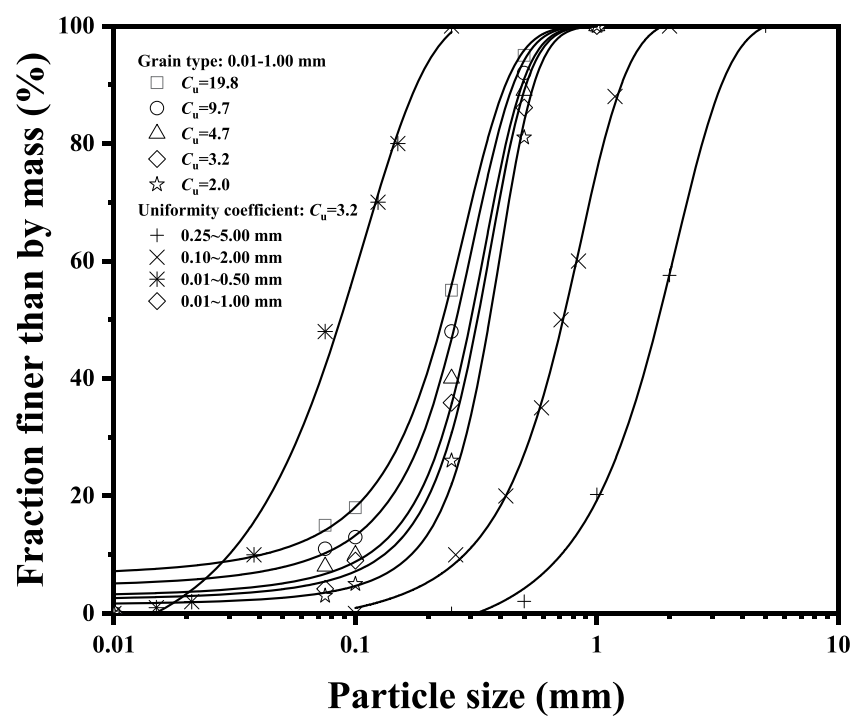

Figure 1. Gradations of the fused quartz used in this study.

\section{Materials and methods}

Fused quartz. Transparent soils are produced by mixing the fused quartz and a refractive index matched pore fluid ${ }^{4}$. The fused quartz has similar geotechnical properties to the nature sand and the fused quartz is highly angular and possesses chemical composition similar to that of natural silicate sand ${ }^{5}$. The main advantages of transparent soil over previous recipes include lower pore fluid viscosity, lower fluid sensitivity to temperature variations, and the ability to recycle the materials for use in multiple tests ${ }^{5}$. More details on the physical and mechanical properties of the fused quartz can be found in the literatures ${ }^{5,6,16-18}$.

In this paper, the fused quartz with a purity of $99.9 \%$, manufactured by Xuzhou Xinyi Wanhe Minerals Co., Ltd., China, was chosen as transparent granular particles to mimic natural sand particles ${ }^{6,19}$. This fused quartz is a kind of angular uranium glass particles, owing to crushing of the production process. According previous application study of transparent soil ${ }^{7,8}$, four difference particle sizes with $0.50 \sim 1.00 \mathrm{~mm}, 0.01 \sim 1.00 \mathrm{~mm}, 0.01 \sim 2.00 \mathrm{~mm}$, and $0.25 \sim 5.00 \mathrm{~mm}$ were used in this experiment, which can obtain by sieving and mixing, as shown in Figure 1 . The specific gravity of the fused quartz is 2.14 . Previous literature shows that the relationships between thermal conductivity $(\lambda)$ and uniformity coefficients $\left(C_{\mathrm{u}}=d_{60} / d_{10}\right)$ for different porosity are parallel, indicating that the gradation effect on the thermal conductivity is attributed to the same intrinsic mechanism, which is independent of the porosity ${ }^{15}$. Hence, uniformity coefficient $\left(C_{\mathrm{u}}=3.2\right)$ for different particle size was also considered for the fused quartz in this study. Basic properties of these samples are shown in Table 1.

Testing methods. Steady state method and transient method are the two main test principles of thermal properties measurement. In this study, the KD2 Pro thermal properties analyzer developed by METER Group, Inc. USA, was used as the test instrument, which belongs to transient method ${ }^{15}$. The KD2 Pro thermal properties analyzer is widely utilized as a tool to research thermal conductivity of soil ${ }^{15,20,21}$. The test probe is selected as the $\mathrm{SH}-1$ probe with an accuracy of $5 \%$, and $30 \mathrm{~mm}$ length. The measurement medium with a thickness of $1.5 \mathrm{~cm}$ or more in any direction around the sensor is guaranteed. More information about the instrument may be seen in the KD2 Pro Manual. The soil sample was tested with a diameter of $50 \mathrm{~mm}$ and a height of $70 \mathrm{~mm}$. The specimen preparation and experimental procedures are as follows:

(1) The fused quartz was placed in an oven setting temperature of $105^{\circ} \mathrm{C}$ for $24 \mathrm{~h}$, then sands were permitted to cool before sieving to different gradations. Maximum and minimum dry density of the fused quartz with the different particle size are shown in Table 1, measuring based on ASTM D4253 (ASTM 2016a) and ASTM D4254 (ASTM 2016b).

(2) Specimens with different porosity and the uniformity coefficients are shown in Table 1 and were prepared according to the four particle sizes in Figure 1. The under compaction method proposed by Ladd ${ }^{22}$ was used to obtain uniform specimens. Five layers were controlled, and a layer forms with its compacted dry density slightly greater (approximately $1 \%$ ) than that of the substratum layer ${ }^{15}$. Compaction was not observed to further alter the gradations.

(3) The $\mathrm{SH}-1$ probe was inserted into the center position of the specimen using a guide to ensure verticality. The thermal conductivity of the fused quartz species was measured by the KD2 Pro thermal properties analyzer. Although a slight densification of the fused quartz is possible during needle insertion, measurements of the three specimens of $0.01 \sim 1.00 \mathrm{~mm}\left(C_{\mathrm{u}}=3.2\right)$ for $\mathrm{n}=0.40$ were within a $\pm 2 \%$ range of the average value of measured thermal conductivities reported in Table 2, which indicates that this approach is repeatable. The thermal conductivity of the fused quartz was measured under controlled room-temperature conditions $\left(25^{\circ} \mathrm{C} \pm 1^{\circ} \mathrm{C}\right)$ to minimize the influence of the ambient temperature. 


\begin{tabular}{|l|l|l|l|l|l|l|}
\hline Grain range $(\mathbf{m m})$ & $C_{\mathrm{u}}$ & $d_{50}(\mathrm{~mm})$ & $\rho_{\mathrm{d} m a x}\left(\mathrm{~g} / \mathrm{cm}^{3}\right)$ & $\rho_{\mathrm{d} \min }\left(\mathrm{g} / \mathrm{cm}^{3}\right)$ & Porosity & $S_{\mathrm{r}}$ \\
\hline $0.01 \sim 1.00$ & 19.8 & 0.36 & 1.383 & 1.148 & $0.40,0.42,0.44,0.46$ & 0 \\
\hline $0.01 \sim 1.00$ & 9.7 & 0.32 & 1.371 & 1.123 & $0.40,0.42,0.44,0.46$ & 0 \\
\hline $0.01 \sim 1.00$ & 4.7 & 0.30 & 1.365 & 1.106 & $0.40,0.42,0.44,0.46,0.48$ & 0 \\
\hline $0.01 \sim 1.00$ & 3.2 & 0.26 & 1.343 & 1.093 & $0.40,0.42,0.44,0.46,0.48$ & 0 \\
\hline $0.01 \sim 1.00$ & 2.0 & 0.23 & 1.327 & 1.08 & $0.40,0.42,0.44,0.46,0.48$ & 0 \\
\hline $0.25 \sim 5.00$ & 3.2 & 1.74 & 1.463 & 1.162 & $0.36,0.38,0.40,0.42,0.44$ & 0 \\
\hline $0.10 \sim 2.00$ & 3.2 & 0.72 & 1.409 & 1.098 & $0.42,0.44,0.46,0.48$ & 0 \\
\hline $0.01 \sim 0.50$ & 3.2 & 0.09 & 1.27 & 1.054 & $0.42,0.44,0.46,0.48$ & 0 \\
\hline $0.01 \sim 1.00$ & 3.2 & 0.26 & 1.343 & 1.093 & 0.40 & $0.3,0.5,0.8,1.0$ \\
\hline $0.01 \sim 1.00$ & 3.2 & 0.26 & 1.343 & 1.093 & 0.42 & $0.3,0.5,0.8,1.0$ \\
\hline $0.01 \sim 1.00$ & 3.2 & 0.26 & 1.343 & 1.093 & 0.44 & $0.3,0.5,0.8,1.0$ \\
\hline
\end{tabular}

Table 1. Basic properties of fused quartz samples with different situation. Notes: $C_{\mathrm{u}}$ is the uniformity coefficient, $d_{50}$ is mean particle size of the fused quartz, $\rho_{\mathrm{dmax}}$ is the maximum dry density, $\rho_{\mathrm{dmin}}$ is the minimum dry density and $S_{\mathrm{r}}$ is the saturation.

\begin{tabular}{|c|c|c|c|c|c|c|c|}
\hline Grain type (mm) & $C_{\mathrm{u}}$ & Porosity & $\lambda\left(\mathrm{W} / \mathrm{m}^{-1} \mathrm{~K}^{-1}\right)$ & Grain type (mm) & $C_{\mathrm{u}}$ & Porosity & $\lambda\left(\mathrm{W} / \mathrm{m}^{-1} \mathrm{~K}^{-1}\right)$ \\
\hline \multirow{5}{*}{$0.01 \sim 1.00$} & \multirow{5}{*}{2.0} & 0.40 & 0.183 & \multirow{5}{*}{$0.01 \sim 1.00$} & \multirow{5}{*}{19.8} & 0.40 & 0.212 \\
\hline & & 0.42 & 0.176 & & & 0.42 & 0.205 \\
\hline & & 0.44 & 0.173 & & & 0.44 & 0.201 \\
\hline & & 0.46 & 0.166 & & & 0.46 & 0.197 \\
\hline & & 0.48 & 0.160 & & & - & - \\
\hline \multirow{5}{*}{$0.01 \sim 1.00$} & \multirow{5}{*}{3.2} & 0.40 & $0.186 / 0.189 / 0.191$ & \multirow{5}{*}{$0.25 \sim 5.00$} & \multirow{5}{*}{3.2} & 0.36 & 0.212 \\
\hline & & 0.42 & 0.183 & & & 0.38 & 0.204 \\
\hline & & 0.44 & 0.177 & & & 0.40 & 0.197 \\
\hline & & 0.46 & 0.172 & & & 0.42 & 0.189 \\
\hline & & 0.48 & 0.167 & & & 0.44 & 0.185 \\
\hline \multirow{5}{*}{$0.01 \sim 1.00$} & \multirow{5}{*}{4.7} & 0.40 & 0.198 & \multirow{5}{*}{$0.10 \sim 2.00$} & \multirow{5}{*}{3.2} & 0.42 & 0.186 \\
\hline & & 0.42 & 0.193 & & & 0.44 & 0.181 \\
\hline & & 0.44 & 0.185 & & & 0.46 & 0.174 \\
\hline & & 0.46 & 0.183 & & & 0.48 & 0.170 \\
\hline & & 0.48 & 0.177 & & & - & - \\
\hline \multirow{5}{*}{$0.01 \sim 1.00$} & \multirow{5}{*}{9.7} & 0.40 & 0.208 & \multirow{5}{*}{$0.01 \sim 0.50$} & \multirow{5}{*}{3.2} & 0.42 & 0.178 \\
\hline & & 0.42 & 0.203 & & & 0.44 & 0.173 \\
\hline & & 0.44 & 0.196 & & & 0.46 & 0.166 \\
\hline & & 0.46 & 0.191 & & & 0.48 & 0.162 \\
\hline & & - & - & & & - & - \\
\hline
\end{tabular}

Table 2. Test results on thermal conductivity of fused quartz. Notes: $\lambda$ is the thermal conductivity.

\section{Results and analysis}

Experimental results of thermal conductivity of the fused quartz. The relationships between thermal conductivity and porosity for the different $C_{\mathrm{u}}$ are parallel in Figure 2. It indicates that the gradation effect on the thermal conductivity is attributed to the same intrinsic mechanism, which is independent of the void ratio. Figure 2 shows that the thermal conductivity at a given porosity increased with the increasing of uniformity coefficient $\left(C_{u}\right)$ when $2.0<C_{\mathrm{u}} \leq 4.7$, and increased gradually when $C_{\mathrm{u}}>4$.7. Similar results are also obtained for Carbonate sand ${ }^{15}$.

Relationships between thermal conductivity of the fused quartz and porosity in different grain type are shown in Figure 3. In order to preserve clarity and avoid overlapping, the error bars (within the precision range of $\pm 5 \%$ of the KD2 Pro thermal properties analyzer) were applied to one set of data. It shows that the thermal conductivity decreases with the increase of porosity, which is in accordance with the results reported by Luikov' ${ }^{23}$, Baldi et al. ${ }^{24}$, Côté \& Konrad $^{25}$, and Barry-Macaulay et al ${ }^{26}$. Figure 3 shows that the thermal conductivity increased with the increasing of the mean particle size with the same uniformity coefficient which is same with the founding of Rzhevsky et al. ${ }^{13}$ For explanation of trend change in Figure 3, soil elements were simplified as follow Figure 4. When heat flows in Figure 4(a), the number of heat transfer paths from solid to air is more than in Figure 4(b). Heat transfer paths of Figure 4(b) in continuous solid are more than Figure 4(a). So the thermal conductivity increased with the increasing of the mean particle size, as shown in Figure 3. For the decrease of porosity, it is like Figure 4(a) to (c). There are more solid particles in the same volume. Thermal conductivity of fused quartz is greater than that of air. With the increasing of porosity, air content of soils increased. Then the thermal conductivity of fused quartz decreased ${ }^{27}$. 


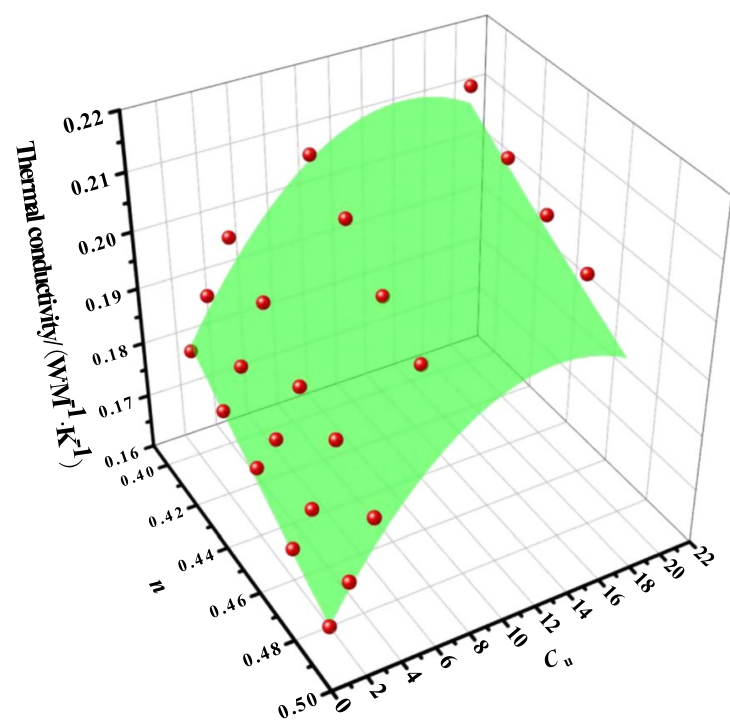

Figure 2. Relationships among the porosity and the thermal conductivity of fused quartz in different uniformity coefficient.

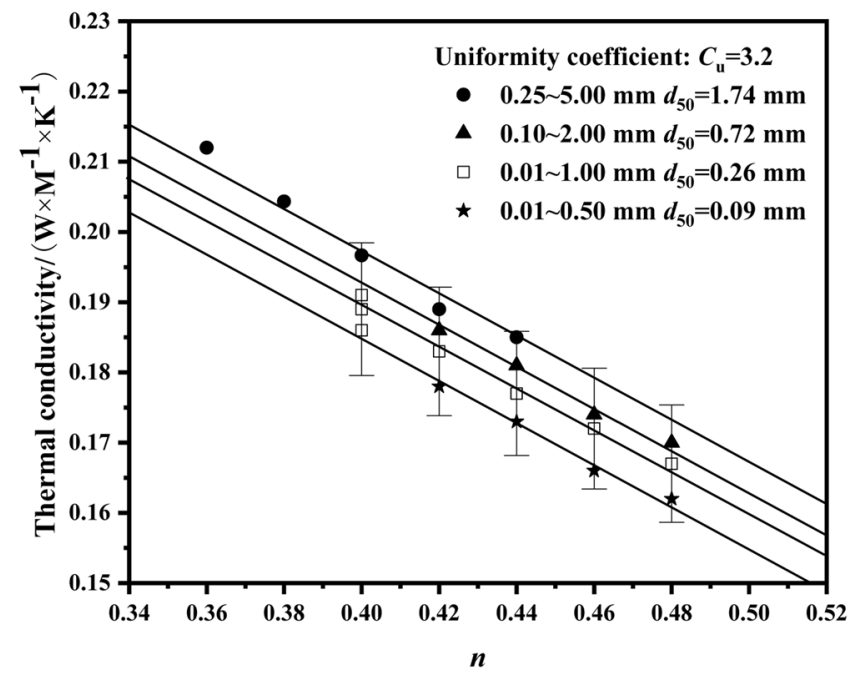

Figure 3. Relationships between thermal conductivity of fused quartz and porosity in different grain type.
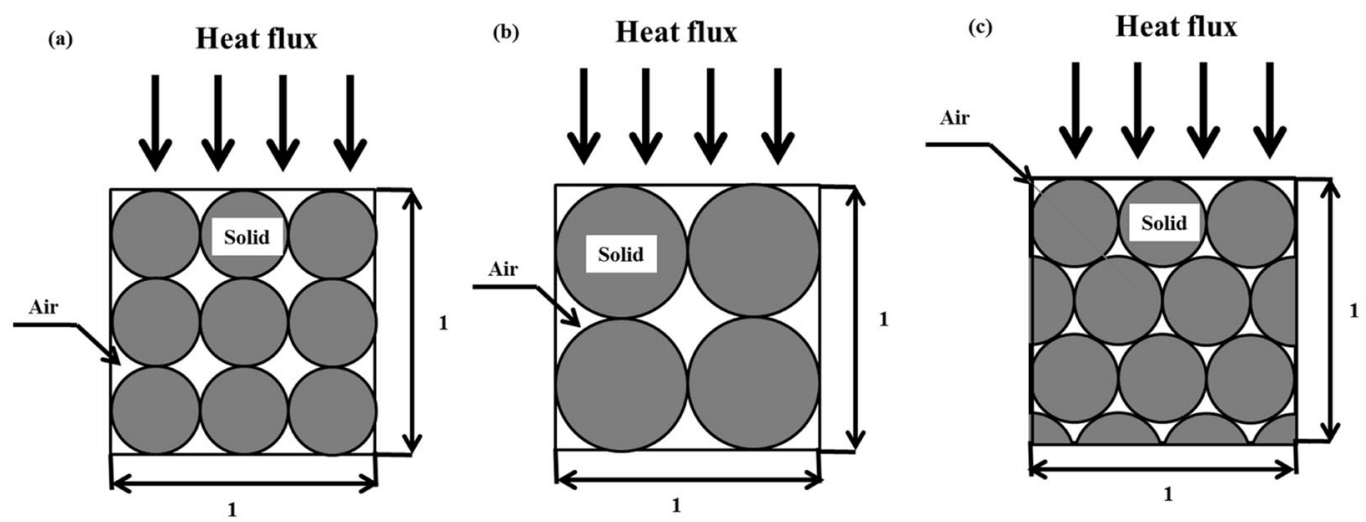

Figure 4. Soil particles per unit volume in ideal arrangement. 


\begin{tabular}{|c|c|c|c|c|c|c|c|c|}
\hline \multirow{2}{*}{$\begin{array}{l}\text { Grain type (mm) } \\
C_{\mathrm{u}}\end{array}$} & \multicolumn{5}{|c|}{$0.01 \sim 1.00$} & $0.25 \sim 5.00$ & $0.10 \sim 2.00$ & $0.01 \sim 0.50$ \\
\hline & 2.0 & 3.2 & 4.7 & 9.7 & 19.8 & \multicolumn{3}{|l|}{3.2} \\
\hline Modified Vincent model (Vincent et al. ${ }^{26}$ ) & 4.26 & 5.01 & 4.94 & 3.77 & 4.32 & 4.12 & 3.51 & 3.34 \\
\hline Modified Tong model (Tong et al. ${ }^{13}$ ) & 8.08 & 8.00 & 6.91 & 6.04 & 5.88 & 4.10 & 5.50 & 8.25 \\
\hline Modified Johansen model (Johansen ${ }^{24}$ ) & 3.24 & 3.86 & 3.81 & 2.79 & 3.32 & 2.87 & 4.13 & 2.91 \\
\hline Vincent model (Vincent et al. $^{26}$ ) & 35.23 & 36.35 & 40.64 & 42.63 & 43.83 & 36.36 & 39.34 & 36.48 \\
\hline Tong model (Tong et al. ${ }^{18}$ ) & 12.31 & 13.82 & 19.51 & 22.05 & 23.71 & 13.67 & 17.67 & 13.84 \\
\hline Johansen model (Johansen ${ }^{24}$ ) & 32.34 & 30.74 & 21.77 & 17.68 & 15.53 & 31.59 & 23.40 & 29.10 \\
\hline
\end{tabular}

Table 3. RRMSE (\%) of predicted thermal conductivity of fused quartz using modified models.

The fitting lines show the relationship between thermal conductivity with porosity for different grain type in Figure 3. This simple linear function ${ }^{28}$ describes the relationship between $\lambda_{\text {dry }}$ and $n$ for mineral soils:

$$
\lambda=c+d n
$$

where $c$ and $d$ are the empirical parameters, depending on the textures, quartz contents and mineral composition, and the value range of $n$ depends on the maximum and minimum voids that fused quartz can reach to. Eq. (1) was provided by Lu et al. ${ }^{28}$ based on Johansen ${ }^{29}$ data and heat pulse data. In this literature, $c=0.51$ and $d=-0.56$ for $0.2<n<0.6$. After that He et al..$^{30}$ also adopted this linear model and proposed different parameters: $c=0.50$ and $d=-0.58$ for a wide range of textures and quartz contents, which are similar with Lu et al. ${ }^{28}$, while $c=1.18$ and $d=-1.92$ for calculating the thermal conductivity of sands with $>99 \%$ quartz contents. Based on these two literatures, the values of $c$ and $d$ depend on the textures and quartz contents. Since fused quartz is different from traditional soils, the values of $c$ and $d$ are different from literatures. For fused quartz, $d=-0.3$, shown in Figure 3 .

Prediction of the thermal conductivity of fused quartz. The root relative mean square error (RRMSE) as show as Eq. (2) is used to evaluate the results of calculation using literature models in Table 3.

$$
R R M S E=\sqrt{\frac{1}{N} \sum_{1}^{N}\left(\frac{\lambda_{\exp }-\lambda_{c a l}}{\lambda_{\exp }}\right)^{2}} \times 100 \%
$$

where $\lambda_{\exp }$ is the experimental value, and $\lambda_{\text {cal }}$ is the calculative value.

Prediction of the thermal conductivity of fused quartz using literature model. Johansen ${ }^{29}$ improved De Vries ${ }^{11}$ model, and then proposed a semi-empirical relationship to predict the thermal conductivity of dry soils,

$$
\begin{gathered}
\lambda_{d r y}=\frac{0.135 \rho_{d}+64.7}{\rho_{s}-0.947 \rho_{d}} \\
n=1-\frac{\rho_{d}}{\rho_{s}}
\end{gathered}
$$

where $\rho_{\mathrm{d}}$ is the dry density of soils $\left(\mathrm{kg} / \mathrm{m}^{3}\right)$, and $\rho_{\mathrm{s}}$ is the soil particle density $\left(\mathrm{kg} / \mathrm{m}^{3}\right), A=0.135, B=64.8$ and $C=0.947$. For the fused quartz, $\rho_{\mathrm{s}}=2140 \mathrm{~kg} / \mathrm{m}^{3}$. Eq. (4) can be applies for dry, unsaturated and saturated soil. The values of RRMSE almost are more than $20 \%$. Based on De Vries ${ }^{11}$ model, coefficients in Eq. (3) are shown as follow,

$$
\begin{gathered}
A=\lambda_{a} \cdot\left(k_{s} \cdot \lambda_{s} / \lambda_{a}-1\right) \\
B=\lambda_{a} \cdot \rho_{s} \\
C=1+k_{s} \\
k_{s}=1 / 3\left[2 /\left(1+\left(\lambda_{s} / \lambda_{a}-1\right) g_{s}\right)+1 /\left(1+\left(\lambda_{s} / \lambda_{a}-1\right)\left(1-2 g_{s}\right)\right)\right]
\end{gathered}
$$

where $\lambda_{\mathrm{s}}$ is the thermal conductivity of solid, $\lambda_{\mathrm{a}}$ is the thermal conductivity of air, $k_{\mathrm{s}}$ is the weighting shape factor, and it is usually treated as a fitting parameter ${ }^{12}$, and $g_{s}$ is shape value of soil particles. The reason for poor fitting effect using Eq. (3) is improper coefficients values.

Vincent ${ }^{31}$ proposed the equation to predict the thermal conductivity of dry soils,

$$
\lambda_{d r y}=\frac{\left(p \lambda_{s}-\lambda_{a}\right) \times \rho_{d}+\lambda_{a} G_{s}}{G_{s}-(1-a) \times \rho_{d}}
$$




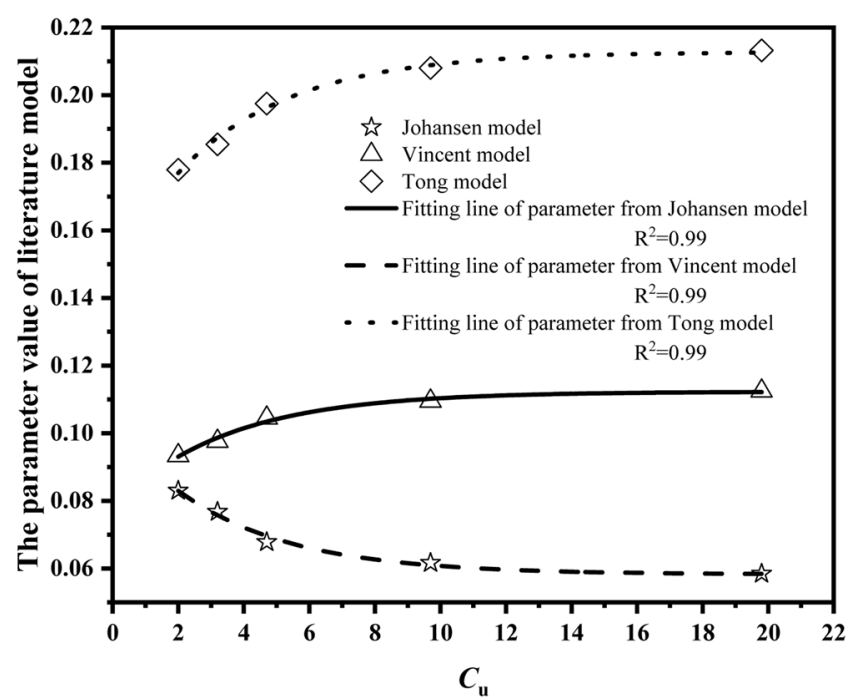

Figure 5. The parameter value of literature model versus $C_{\mathrm{u}}$ for fused quartz.

where $G_{\mathrm{s}}$ is the specific gravity, and $p$ is the empirical parameter, $p=0.053$. Note that this equation is the same as Eq. (3) when $\lambda_{\mathrm{s}}=3 \mathrm{~W} \bullet \mathrm{m}^{-1} \bullet \mathrm{K}^{-1}, \lambda_{\mathrm{a}}=0.024 \mathrm{~W} \bullet \mathrm{m}^{-1} \bullet \mathrm{K}^{-1}$, and $\rho_{\mathrm{d}}=2.7 \mathrm{~g} \bullet \mathrm{cm}^{-3}$. For the fused quartz, substitute Eq. (4) into Eq. (9), and $\lambda_{\mathrm{s}}=1.4 \mathrm{~W} \bullet \mathrm{m}^{-1} \bullet \mathrm{K}^{-132}$. The values of RRMSE are more than $30 \%$ that is not enough for the accuracy of predicting the thermal conductivity of fused quartz. The reason for poor fitting effect using Eq. (9) is improper coefficients value.

Substitute Eq. (4), (5), (6) and (7) into Eq. (3), we can get,

$$
\lambda_{d r y}=\frac{\left(k_{s} \lambda_{s}-\lambda_{a}\right)(1-n)+\lambda_{a}}{1-\left(1-k_{s}\right)(1-n)}
$$

Substitute Eq. (4) into Eq. (9), we can get,

$$
\lambda_{d r y}=\frac{\left(p \lambda_{s}-\lambda_{a}\right)(1-n)+\lambda_{a}}{1-(1-p)(1-n)}
$$

where $p$, just like $k_{\mathrm{s}}$, is the weighting shape factor, and it is usually treated as a fitting parameter at Eq. (9).

Tong et al. ${ }^{33}$ improved Wiener model, and then proposed a semi-empirical semi-theoretical model to predict the thermal conductivity of dry soils.

$$
\lambda_{d r y}=\eta_{1}(1-n) \lambda_{s}+\eta_{1} n \lambda_{a}+(1-n) \frac{\lambda_{a} \lambda_{s}}{n \lambda_{s}+(1-n) \lambda_{a}}
$$

where parameter $\eta_{1}$ usually can be obtained by a series of experiments that require the samples of different porosities but with zero saturation (dry samples), and Tong provide an empirical equation about $\eta_{1}$ considering Johansen model $^{29}$. In a sense, parameter $\eta_{1}$ describes the way of contact between soil particles.

$$
p=0.0692 n^{-0.7831}
$$

For fused quartz, $\lambda_{\mathrm{s}}=1.4 \mathrm{~W} \bullet \mathrm{m}^{-1} \bullet \mathrm{K}^{-1}$. The values of RRMSE are more than $10 \%$ which is not enough for the accuracy of predicting the thermal conductivity of fused quartz. Obviously Eq. (13) was obtained by Eq. (3), it is not surprising that the fitting effect of Eq. (13) is poor for fused quartz.

Modified literature models. For Johansen model, Vincent model and Tong model, parameter can be modified as follow:

$$
\eta_{1}=k_{s}=p=a-b \times 0.75^{C_{u}}
$$

where for Johansen model $a=0.06$ and $b=-0.04$, for Vincent model, $a=0.11$ and $b=0.03$, and for Tong model, $a=0.21$ and $b=0.06$, shown in Figure 5. Eq. (14) provides a relationship for the effect of particle composition on thermal conductivity. In this study, $a$ and $b$ are empirical parameters. $a$ is the maximum value of the coefficient, while $b$ control the rate of change of the coefficient.

Figure 6 presents the comparison between predicted thermal conductivity using (a) modified Vincent model; (b) modified Johansen model; and (c) the modified Tong model and measured thermal conductivity of the fused quartz. It is evident that the predicted values compare well with the measured values for the modified Vincent 

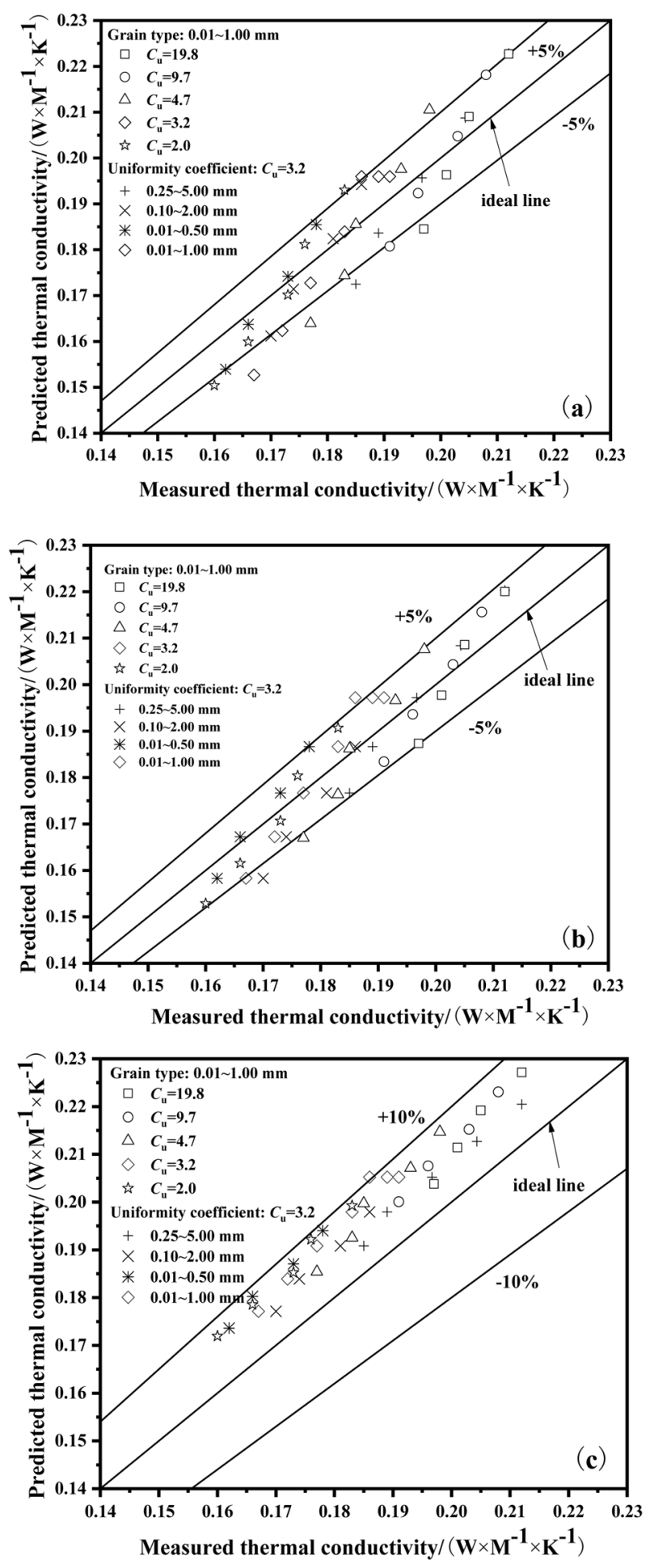

Figure 6. Predicted thermal conductivity values versus measured values using (a) modified Vincent model ; (b) modified Johansen model; and (c) the modified Tong model.

model and modified Johansen model, almost in the $\pm 5 \%$ range, and the modified Tong model is higher than measured thermal conductivity in the $\pm 10 \%$ range.

The values of root relative mean square error using modified Johansen model, modified Vincent model and modified Tong model are shown in Table 3. It shows that for modified Johansen model the values of RRESM are between $2 \%$ and 5\%, for modified Vincent model the values of RRESM are between 3\% and 5\%, and for modified Tong model the values of RRESM are almost between $4 \%$ and $9 \%$. 


\begin{tabular}{|l|l|l|l|l|l|}
\hline$C_{\mathbf{u}}$ & $\mathbf{2 . 0}$ & $\mathbf{2 . 8}$ & $\mathbf{4 . 7}$ & $\mathbf{9 . 7}$ & $\mathbf{1 9 . 8}$ \\
\hline Modified Vincent model (Vincent et al ${ }^{26}$ ) & 1.04 & 2.11 & 1.71 & 0.81 & 1.36 \\
\hline Modified Tong model (Tong et al. ${ }^{13}$ ) & 2.14 & 2.00 & 1.14 & 2.36 & 1.44 \\
\hline
\end{tabular}

Table 4. RRMSE (\%) of predicted thermal conductivity of Carbonate sand ${ }^{15}$ using modified models.

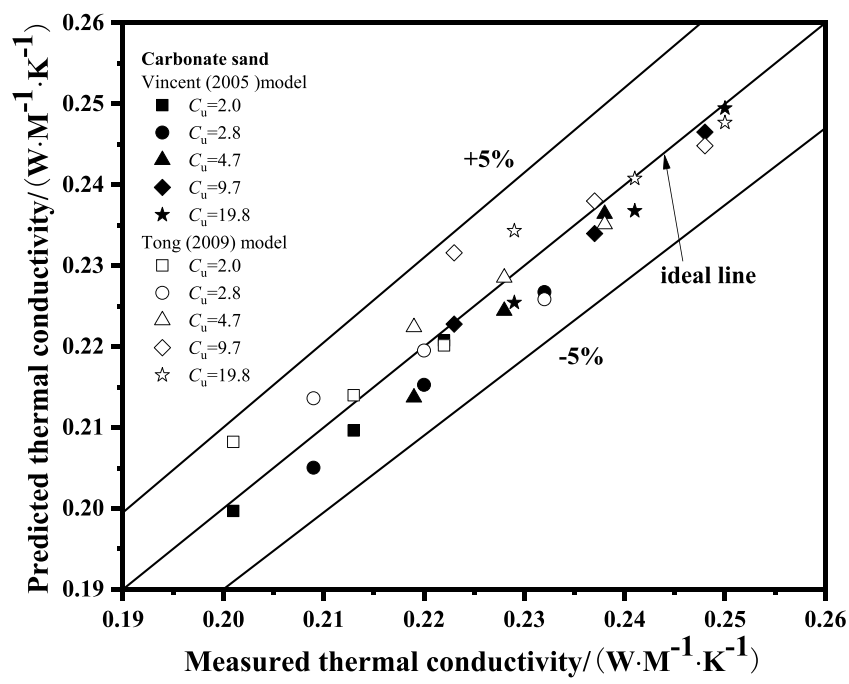

Figure 7. Predicted thermal conductivity values using modified models versus Carbonate sand ${ }^{15}$.

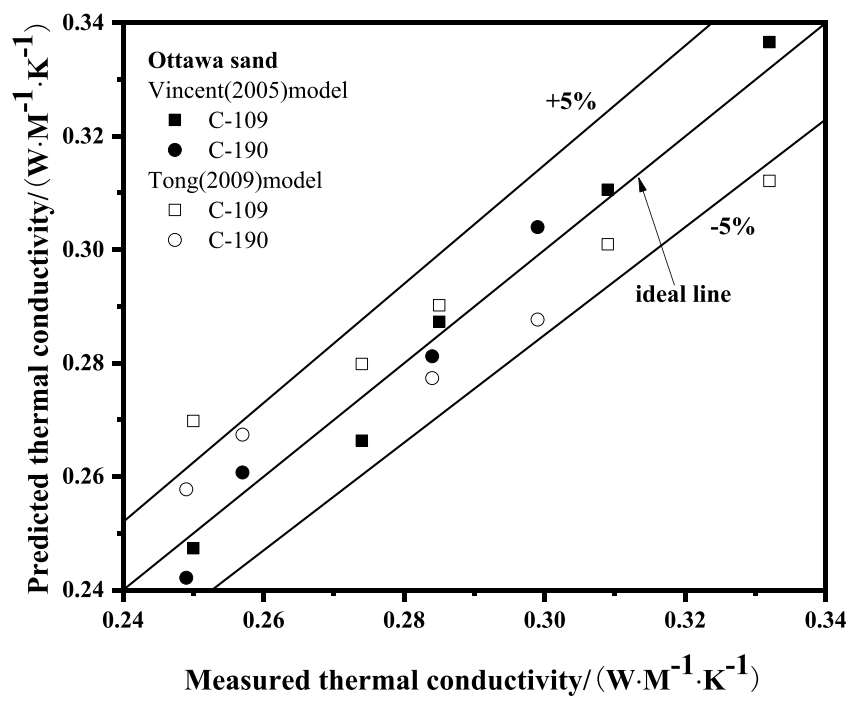

Figure 8. Predicted thermal conductivity values using modified models versus Ottawa sand ${ }^{12}$.

Modified literature models for literature data. The thermal conductivity of carbonate sand ${ }^{15}$ was predicted by using the modified Vincent model and modified Tong model: for Vincent model, $a=0.038$ and $b=0.09$, while for Tong model, $a=0.071$ and $b=0.018$. Figure 7 presents the comparison between predicted thermal conductivity using the modified Vincent model and modified Tong model and measured thermal conductivity of carbonate sand. It is evident that the predicted values compare well with the measured values, in the $\pm 5 \%$ range. The values of root relative mean square error using modified Vincent model and modified Tong model are shown in Table 4 . The values of RRESM of predicted thermal conductivity of Carbonate sand ${ }^{15}$ using modified models are between $0 \%$ and $3 \%$.

The thermal conductivity of Ottawa sand ${ }^{12}$ was also predicted by using the modified Vincent model and modified Tong model: for Vincent model, $a=0.029$ and $b=0.01$, while for Tong model, $a=0.099$ and $b=0.077$. Figure 8 presents the comparison between predicted thermal conductivity using the modified Vincent model and modified Tong model and measured thermal conductivity of Ottawa sand. It is evident that the predicted values compare well with the measured values, in the $\pm 5 \%$ range. The values of root relative mean square error of 

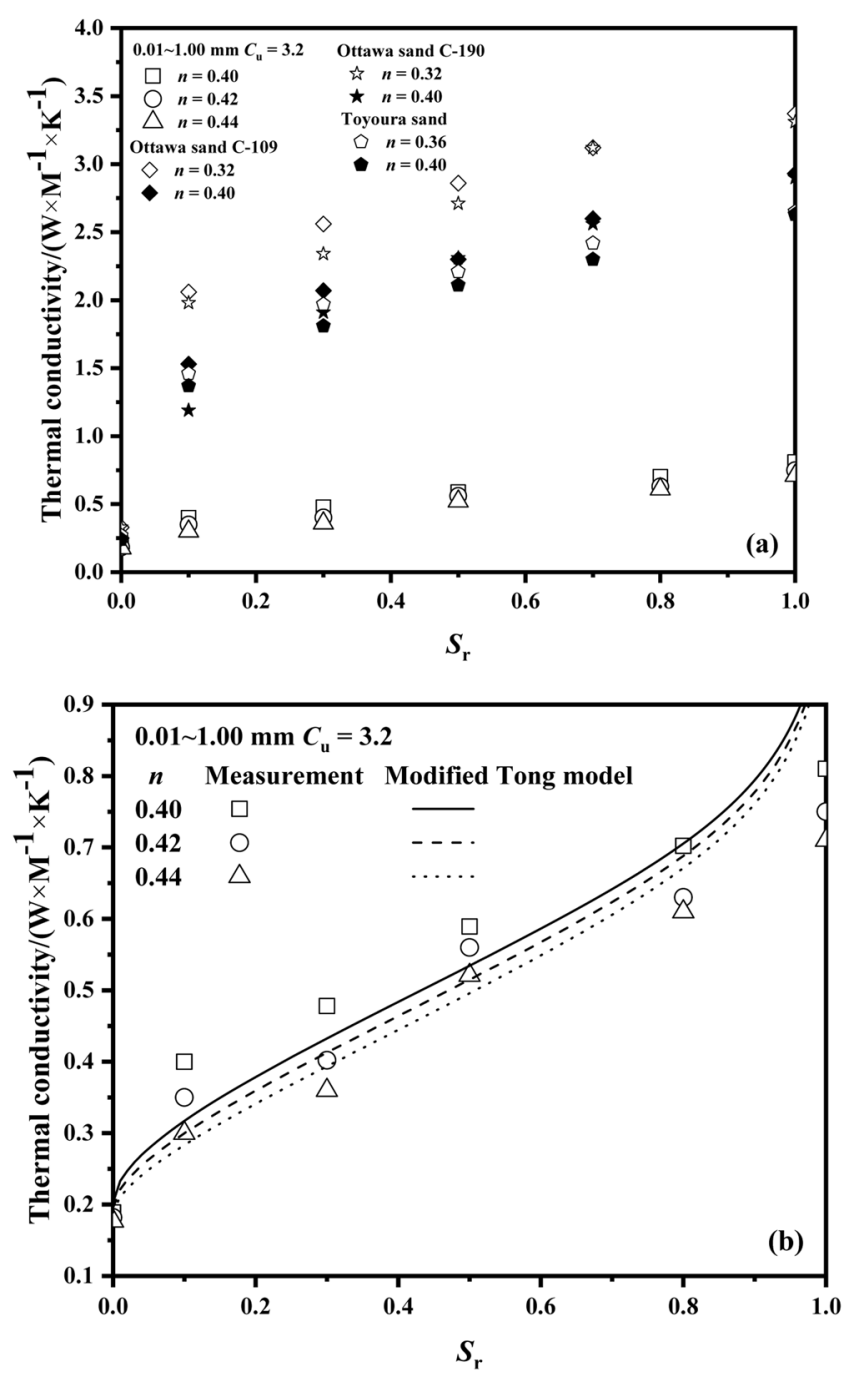

Figure 9. Thermal conductivity versus saturation of (a) comparison between fused quartz and natural sands ${ }^{12}$; and (b) fused quartz.

\begin{tabular}{|l|l|l|l|}
\hline $\boldsymbol{n}$ & $\mathbf{0 . 4 0}$ & $\mathbf{0 . 4 2}$ & $\mathbf{0 . 4 4}$ \\
\hline Tong model & 20.09 & 19.38 & 19.25 \\
\hline Modified Tong model & 16.03 & 15.30 & 15.33 \\
\hline
\end{tabular}

Table 5. RRMSE (\%) of predicted thermal conductivity of fused quartz from dryness to full saturation using the Tong model modified and Tong model.

Ottawa sand C-109 using modified Vincent model and modified Tong model are $1.54 \%$ and 4.76\%, respectively. The values of root relative mean square errors of Ottawa sand C-190 using modified Vincent model and modified Tong model are $1.83 \%$ and $3.48 \%$, respectively. The values of RRESM of predicted thermal conductivity of Ottawa sand using modified models are between $0 \%$ and $5 \%$.

Modified Tong model for the three-phase mixture. In order to verify the new modified Tong model, a set of samples were tested at different degrees of saturation from dryness to full saturation. The measurement results are shown in Figure 9(a). The values of thermal conductivity for natural sands are higher than that of fused quartz due to the difference in minerals. At a low $S_{\mathrm{r}}$ range, $0<S_{\mathrm{r}}<0.1$, a sharp increase by about $100 \%$ with $S_{\mathrm{r}}$ was observed, while for $0.1<S_{\mathrm{r}}<1$, the rate of linear increase was about $100 \%$.

Tong et al. ${ }^{33}$ also proposed a semi-empirical semi-theoretical model to predict the thermal conductivity of the three-phase. 


$$
\begin{aligned}
& \lambda=\eta_{1}(1-n) \lambda_{s}+\left(1-\eta_{2}\right)\left[1-\eta_{1}(1-n)\right]^{2} \times \\
& {\left[\frac{(1-n)\left(1-\eta_{1}\right)}{\lambda_{s}}+\frac{n S_{r}}{\lambda_{w}}+\frac{n\left(1-S_{r}\right)}{\lambda_{g}}\right]^{-1}} \\
& +\eta_{2}\left[(1-n)\left(1-\eta_{1}\right) \lambda_{s}+n S_{r} \lambda_{w}+n\left(1-S_{r}\right) \lambda_{g}\right]
\end{aligned}
$$

where parameter $\eta_{2}$ should be a function of porosity and saturation, $\eta_{2}=0.59 S_{r}^{1.487 n-0.0404}$.

The calculation results using modified Tong model are shown in the Figure 9(b). RRMSE (\%) of predicted thermal conductivity of fused quartz from dryness to full saturation using modified the Tong model modified and Tong model is shown in Table 5. For each porosity, the values of RRMSE reduced by $4 \%$.

\section{Conclusions}

In this study, the thermal conductivity of fused quartz is first measured, and three empirical predicted models are modified for calculating the thermal conductivity of fused quartz. Nearly 100 test results from previous literature are used to verification the modified empirical predicted models. Following conclusions can be drawn:

(1) The thermal conductivity at a given porosity increases with the increasing of the uniformity coefficient when $2.0<C_{\mathrm{u}} \leq 4.7$, and it increases gradually when $C_{\mathrm{u}}>4.7$. The thermal conductivity decreases with the increasing of the porosity, and increased with the increasing of the mean particle size with the same uniformity coefficient.

(2) Three modified models (Vincent model, Tong model, and Johansen model) can be used for predicting the thermal conductivity of fused quartz with acceptable precision. A simple modified method to estimate the value of thermal conductivity has been proposed, and its utility and efficiency have been demonstrated successfully by conducting the fused quartz, carbonate sand and Ottawa sand.

Received: 4 December 2019; Accepted: 9 March 2020;

Published online: 16 April 2020

\section{References}

1. Younger, P. L. Missing a trick in geothermal exploration. Nature Geoscience 7(7), 479-480 (2014).

2. Huang, S. Geothermal energy in China. Nature Climate Change 2(8), 557-560 (2012).

3. Moore, J. N. \& Simmons, S. F. Geophysics. more power from below. Science 340(6135), 933-934 (2013).

4. Zhuang, W., Chi, L. I. \& Xuan-Ming, D. Application of transparent soil model tests to study the soil-rock interfacial sliding mechanism. Journal of Mountain Science 16(04), 214-222 (2019).

5. Iskander, M., Bathurst, R. J. \& Omidvar, M. Past, present, and future of transparent soils. Geotechnical Testing Journal 38(5), 557-573 (2015).

6. Kong, G., Li, H., Yang, Q., Meng, Y. \& Xu, X. Cyclic undrained behavior and liquefaction resistance of transparent sand manufactured by fused quartz. Soil Dynamics and Earthquake Engineering 108, 13-17 (2018).

7. Black, J. A. \& Tatari, A. Transparent soil to model thermal processes: an energy pile example. Geotechnical Testing Journal 38(5), 752-764 (2015)

8. Siemens, G. A., Mumford, K. G. \& Kucharczuk, D. Characterization of transparent soil for use in heat transport experiments. Geotechnical Testing Journal 38(5), 620-630 (2015).

9. Zhang, N. \& Wang, Z. Review of soil thermal conductivity and predictive models. International Journal of Thermal Sciences 117(7), 172-183 (2017)

10. Dong, Y., Mccartney, J. S. \& Lu, N. Critical review of thermal conductivity models for unsaturated soils. Geotechnical and Geological Engineering 33(2), 207-221 (2015).

11. De Vries, D. Thermal properties of soil, Physics of plant environment, 210-235 (Amsterdam, 1963).

12. Tarnawski, V. R. et al. conductivity of standard sands. Part I. Dry-State Conditions. International Journal of Thermophysics 30(3), 949-968 (2009).

13. Rzhevskyv, N. Compaction of argillaceous sediments. Developmentsin Sedimentology, Amsterdam: Elsevier, 16 (1971)

14. Midttomme, K. \& Roaldset, E. The effect of grain size on thermal conductivity of quartz sands and silts. Petroleum Geoscience 4(2), $165-172(1998)$

15. Xiao, Y., Liu, H. L., Nan, B. W. \& McCartney, J. S. Gradation-dependent thermal conductivity of sands, Journal of Geotechnical and Geoenvironmental Engineering 144(9) (2018).

16. Ezzein, F. M. \& Bathurst, R. J. A transparent sand for geotechnical laboratory modeling. Geotechnical Testing Journal 34(6), 1-12 (2011).

17. Guzman, I. Development of a transparent soil for simulating projectile penetration into granular materials, $\mathrm{PhD}$ thesis, Polytechnic Institute of New York Univ., Brooklyn (New York 2014).

18. Guzman, I. L., Iskander, M., Suescun-Florez, E. \& Omidvar, M. A transparent aqueous-saturated sand surrogate for use in physical modeling. Acta Geotechnica 9, 187-206 (2014).

19. Kong, G. et al. Investigation on shear modulus and damping ratio of transparent soils with different pore fluids. Granular Matter 20(1), 8 (2018).

20. Nikoosokhan, S., Nowamooz, H. \& Chazallon, C. Effect of dry density, soil texture and time-spatial variable water content on the soil thermal conductivity, Geomechanics and Geoengineering, 1-10 (2015).

21. Xiao, Y., Nan, B. \& McCartney, J. S. Thermal Conductivity of Sand-Tire Shred Mixtures, Journal of Geotechnical and Geoenvironmental Engineering, 145(11) (2019).

22. Ladd, R. S. Preparing test specimens using undercompaction. Geotechnical Testing Journal 1(1), 16-23 (1978).

23. Luikov, A. V. Systems of differential equations of heat and mass transfer in capillary-porous bodies (review). International Journal of Heat and Mass Transfer 18(1), 1-14 (1975).

24. Baldi, G., Hueckel, T. \& Pellegrini, R. Thermal volume changes of the mineral-water system in low-porosity clay soils. Canadian Geotechnical Journal 25(4), 807-825 (1988). 
25. Côté, J. \& Konrad, J. A generalized thermal conductivity model for soils and construction materials. Canadian Geotechnical Journal 42, 443-458 (2005).

26. Barry-Macaulay, D., Bouazza, A., Singh, R. M., Wang, B. \& Ranjith, P. G. Thermal conductivity of soils and rocks from the Melbourne (Australia) region. Engineering Geology 164, 131-138 (2013).

27. Incropera, F. P. Fundamentals of heat and mass transfer (ed. John Wiley and Sons) (New York, 1990).

28. Lu, S., Ren, T., Gong, Y. \& Horton, R. An improved model for predicting soil thermal conductivity from water content at room temperature. Soil Science Society of America Journal 71(1), 8-14 (2007).

29. Johansen, O. Thermal conductivity of soils, $\mathrm{PhD}$ thesis, Norwegian University of Science and Technology (Trondheim 1977).

30. He, H. et al. A modified normalized model for predicting effective soil thermal conductivity. Acta Geotechnica 12(6), 1281-1300 (2017).

31. Balland, V. \& Arp, P. A. Modeling soil thermal conductivities over a wide range of conditions. Journal of Environmental Engineering and Science 4(6), 549-558 (2005).

32. Clauser, C. \& Huenges, E. Thermal conductivity of rocks and minerals, Rock Physics \& Phase Relations, American Geophysical Union (AGU) (1995).

33. Tong, F., Jing, L. \& Zimmerman, R. W. An effective thermal conductivity model of geological porous media for coupled thermohydro-mechanical systems with multiphase flow. International Journal of Rock Mechanics Mining Sciences 46(8), 1358-1369 (2009).

\section{Acknowledgements}

This work was supported by National Natural Science Foundation of China (No. 51922037).

\section{Author contributions}

Zhang and Kong wrote the main manuscript text and Wang and Xu provided the lab and some advice.

\section{Competing interests}

The authors declare no competing interests.

\section{Additional information}

Correspondence and requests for materials should be addressed to G.Q.K.

Reprints and permissions information is available at www.nature.com/reprints.

Publisher's note Springer Nature remains neutral with regard to jurisdictional claims in published maps and institutional affiliations.

Open Access This article is licensed under a Creative Commons Attribution 4.0 International License, which permits use, sharing, adaptation, distribution and reproduction in any medium or format, as long as you give appropriate credit to the original author(s) and the source, provide a link to the Creative Commons license, and indicate if changes were made. The images or other third party material in this article are included in the article's Creative Commons license, unless indicated otherwise in a credit line to the material. If material is not included in the article's Creative Commons license and your intended use is not permitted by statutory regulation or exceeds the permitted use, you will need to obtain permission directly from the copyright holder. To view a copy of this license, visit http://creativecommons.org/licenses/by/4.0/.

(c) The Author(s) 2020 